\title{
Razão, racionalidade, decisão racional: o que a filosofia da ação tem a dizer para a economia (e vice-versa)?
}

\author{
Reason, rationality and rational decision: \\ what the philosophy of action has to say to economics (and vice versa)?
}

\author{
Brena Paula Magno Fernandez ${ }^{1}$ \\ brenafernandez@hotmail.com \\ Universidade Federal de Santa Catarina (UFSC)
}

\begin{abstract}
Resumo: Neste artigo, à luz da filosofia da ação, analisa-se o papel da racionalidade na economia tradicional. Nosso intuito foi problematizar o papel normativo exercido pela racionalidade na filosofia da ação contrapondo-o ao papel positivo por ela exercido na economia (seja em sua versão mainstream, seja em sua versão comportamental). Na conclusão, sob três pontos de vista distintos, nomeadamente o normativo, o positivo e o normativo-positivo, procura-se examinar a questão se os supostos "irracionalismos" do comportamento econômico observados nos testes empíricos da economia comportamental de fato colocam em questão os padrões de racionalidade estabelecidos pelas chamadas teorias canônicas da racionalidade.
\end{abstract}

Palavras-chave: Economia; Filosofia da Ação; Economia Comportamental; Razão; Racionalidade

\begin{abstract}
In this article, in the light of philosophy of action, we analyze the role of rationality in economics. Our intention is to confront the normative role played by rationality in the philosophy of action with its positive role played in economics (whether it is in its mainstream version, or it is in its behavioral version). The conclusion seeks to examine the question whether the alleged "irrationalism" of economic behavior observed in empirical tests of behavioral economics really call into question the rationality standards set by so called canonical theories of rationality under three different points of view, namely the normative, the positive and the normative-positive ones.
\end{abstract}

Keywords: Behavioral Economics; Economics; Philosophy of Action; Reason; Rationality

Recebido em: 06-11-2017. Aceito em: 05-12-2017.

\footnotetext{
${ }^{1}$ Uma versão anterior deste artigo foi redigida como parte das atividades de pesquisa desenvolvidas no Mind, Language, Action Group (MLAG), do Instituto de Filosofia da Universidade do Porto. A autora agradece o apoio financeiro da Capes (Estágio Sênior no Exterior - Processo $n^{\circ}$ 002627/2015-09), bem como os valiosos comentários e sugestões dos pareceristas anônimos da revista. Valem no entanto as isenções de praxe no que toca a responsabilidade em relação às conclusões aqui extraídas.
} 


\section{INTRODUÇÃO}

Há uma relação imediata entre a filosofia da ação e a economia, nomeadamente aquela que se estabelece em virtude do fato de que uma das categorias essenciais subjacentes ao pensamento econômico ser o conceito de racionalidade. Com efeito, dentre todas as ciências sociais, foi a economia a única a lançar mão de um conceito de racionalidade com vistas a demarcar o seu objeto de estudo. Ocorre que a caracterização do conceito de racionalidade é também uma questão fulcral para a filosofia da ação. Dentre os principais problemas que esta disciplina se propõe a tratar encontram-se: i) o problema da natureza da ação, que consiste em investigar o que faz com que um determinado tipo de evento possa ser legitimamente considerado como uma ação (ou seja, procura estabelecer um critério claro de demarcação entre ações e não-ações), ii) o problema da individuação de ações/eventos (ou seja, distinguir as ações e os eventos uns dos outros) e iii) o problema da explicação da ação. As obras dos filósofos Anscombe (1957) e Davidson (1980) são incontornáveis enquanto tentativas de solucionar estas questões.

Uma das categorias fundamentais que é chamada para especificar as distinções necessárias entre aquilo que pode contar como uma ação e aquilo que não pode é a categoria da racionalidade (Fernandez, Veríssimo, Couto, 2017). Neste sentido, a filosofia da ação lida com um aspecto fundador da teoria econômica, que é precisamente o aspecto de determinar o que é ser racional no âmbito da ação. Em contraste aos meros eventos, as nossas ações podem ser racionalizadas, i.e. podem ser descritas por intermédio de um vocabulário intencional que faz uso de termos como crenças e desejos. No entanto, enquanto movimentos corporais, elas são também susceptíveis de uma descrição que recorre apenas a termos não-intencionais.

Assim, uma das muitas questões que a filosofia da ação enfrenta é: como é possível compatibilizar a tese de que as nossas razões - i.e. as causas mentais daquilo que fazemos acontecer - são sui generis em comparação às causas ou eventos físicos? Muito do que concerne ao nosso entendimento sobre nós mesmos e sobre os nossos relacionamentos com outros assenta na caracterização de uma causa mental daquilo que vemos ou fazemos acontecer e que tem subjacente a noção-chave de intencionalidade. No artigo, esta discussão será conduzida à luz do caráter normativo que a filosofia da ação atribui ao conceito de racionalidade.

Também na economia a discussão do conceito da racionalidade e do seu papel nas teorias é fundante. A atribuição do Prêmio Nobel de 2017 a Richard Thaler, reforça uma vez mais uma a importância de um programa de pesquisa relativamente recente: a chamada 
economia comportamental. A sua agenda de discussão propõe desafios tanto para a natureza supostamente positiva (ou descritiva) de alguns pressupostos das teorias econômicas tradicionais como para os próprios fundamentos da teoria da decisão, sendo que no epicentro desta discussão encontra-se o conceito de racionalidade.

$\mathrm{Na}$ verdade, o advento recente de tantos prêmios Nobel para a área de economia comportamental pode ser considerado como o ápice de um movimento bem mais antigo. $\mathrm{O}$ estudo da racionalidade tem sido foco de interesse imenso ao longo das últimas décadas, em áreas que vão desde a filosofia até a cibernética, passando pela economia, psicologia, ciência política e mesmo a biologia evolucionista. Por um lado, o fascínio pelo tema reflete uma curiosidade bastante natural para o ser humano. Afinal, interessa-nos saber por que agimos como agimos. Por outro lado, um mesmo interesse de pesquisa despertado em tantas e tão diversas áreas de investigação sugere também que há muitos aspectos distintos - porém interconectados - que necessitam ser abordados se quisermos alcançar uma compreensão verdadeiramente abrangente acerca dessa questão.

Antes de nos voltarmos para alguns destes múltiplos aspectos e suas inter-relações, no entanto, será útil identificar os propósitos distintos de duas abordagens particularmente dignas de nota nos estudos sobre a racionalidade: as abordagens normativa e positiva.

Como primeira aproximação, podemos reiterar que, para a recém referida filosofia da ação, racionalidade é a característica de qualquer decisão para agir que faz da sua escolha uma necessidade. $\mathrm{O}$ que se busca estabelecer é um conceito normativo sobre o raciocínio no seguinte sentido: agentes racionais devem tirar conclusões consistentes sobre qual curso de ação tomar, dadas as suas crenças, os seus desejos, os seus objetivos, e o leque de informações que se encontra à sua disposição. Refere-se, portanto, à conformidade das ações com as melhores razões para o agir.

A abordagem normativa não se preocupa tanto com a forma como as pessoas efetivamente raciocinam para agir, mas sim com a forma como elas deveriam raciocinar, à luz de algumas teorias formais consideradas como cânones da racionalidade, nomeadamente a lógica, a teoria das probabilidades e a teoria da decisão (Miguens, 2004; Stein, 1996). O objetivo destas teorias é explicitar quais regras ou princípios podem nortear inferências e decisões corretas. Ou seja, elas se dedicam a determinar os melhores padrões de correção a partir dos quais a qualidade do raciocínio humano pode ser ajuizada.

Além desta introdução, o trabalho está dividido em mais três seções. A seção 2 expõe algumas das principais características da abordagem normativa. À luz do caráter normativo atribuído pela filosofia da ação à teoria da decisão, busca-se destacar alguns dos seus aspectos 
centrais, procurando com isso explicitar uma tensão que sempre pareceu existir na ciência econômica. Conforme assinalado acima, a concepção filosófica que subjaz a teoria da decisão nunca entendeu que o seu estatuto fosse outro que não o de uma teoria normativa acerca da racionalidade. Não obstante, durante muito tempo na economia se acreditou, tácita ou explicitamente, que tanto a teoria da decisão quanto o postulado da racionalidade, uma vez utilizados na formulação das teorias econômicas padrão, representavam não o "dever ser", mas principalmente o "é" do comportamento humano. Trata-se da conhecida hipótese da maximização da utilidade esperada por parte do homo oeconomicus. Argumentamos que o artigo seminal de Milton Friedman (1953) é um caso exemplar nesse sentido, tendo fornecido um recurso intelectual engenhoso, que durante vários anos serviu para a consolidação de um duplo papel - simultaneamente positivo e normativo - para o postulado da racionalidade na economia.

Na seção 3, o trabalho trata da abordagem descritiva (ou positiva) da economia comportamental. Tomando por base trabalhos seminais de Kahneman e Tversky, procuramos expor alguns dos elementos mais importantes da teoria das perspectivas. Apresentamos também um breve resumo de alguns dos resultados experimentais mais conhecidos e inquietantes nesta área, fazendo um contraponto entre a teoria das perspectivas e a teoria da utilidade esperada, em particular no que concerne à questão do risco.

Finalmente, na seção das considerações finais, faz-se um apanhado dos temas tratados, buscando-se examinar se os comportamentos observados nos testes empíricos realmente ameaçam a concepção tradicional de racionalidade, seja ela entendida segundo a perspectiva normativa (da filosofia da ação), seja ela entendida segundo a perspectiva positiva (da economia padrão ou da economia comportamental). Ao mapear os cenários alternativos e os papeis possíveis para a teoria da racionalidade, uma terceira opção - nomeadamente a abordagem normativo-positiva adotada por Friedman - também é problematizada.

\section{RACIONALIDADE: A ABORDAGEM NORMATIVA DA TEORIA DA DECISÃO}

Referimos acima que a literatura filosófica especializada identifica três teorias formais como os cânones da racionalidade: a lógica, a teoria das probabilidades e a teoria da decisão. Herdeiros que somos do pensamento analítico - vale dizer, cartesiano -, fomos ensinados a separar os fenômenos, problemas e assuntos em partes, na expectativa de melhor conhecer cada parte individualmente, e presumindo que cada uma das partes possuísse um elevado grau 
de autonomia em relação às demais. No entanto, no caso ora em pauta não podemos esquecer que esse estratagema cognitivo não passa de uma abstração útil.

Sendo mais realistas, a teoria da decisão não pode ser pensada isoladamente, uma vez que não poderia ter surgido sem a existência prévia da teoria das probabilidades, assim como a teoria das probabilidades não poderia ter surgido sem a existência anterior da lógica (clássica). E a ordem temporal em que as teorias canônicas da racionalidade foram elaboradas na história parece corroborar esta tese: que se tratam de arquiteturas conceituais que formam camadas sobrepostas, em que as estruturas exteriores ou superiores dependem das estruturas interiores ou inferiores, e não de estruturas teóricas separadas, individuais e autônomas. Isso explica tanto a importância decisiva hoje atribuída à teoria da decisão como o encaminhamento adotado neste artigo, que trata mais diretamente da terceira e última das teorias canônicas, apenas tangenciando a primeira e a segunda quando se fizer necessário.

Não obstante a chamada lógica clássica ter sido criada no século IV a.C. e as origens da teoria das probabilidades remontarem ao século XVII, é a última das teorias canônicas, elaborada somente em meados do século XX, aquela que hoje é tida como a mais simples, sofisticada e completa teoria da racionalidade. A teoria da decisão é a mais completa das três porque encapsula e pressupõe as duas anteriores. No seu contexto, sempre que tratamos de raciocínios voltados para ações que envolvem algum grau de incerteza, estamos necessariamente pressupondo os resultados alcançados pela teoria das probabilidades ${ }^{2}$ e também necessariamente usando raciocínios alicerçados pela correção de suas inferências, segundo os princípios da lógica clássica. Note-se, porém, que o inverso não é o caso, sendo a lógica independente da teoria das probabilidades, que por sua vez é independente da teoria da decisão. A teoria da decisão racional postula como devemos entender a racionalidade no contexto decisório individual. De modo geral, decidir sempre significa fazer uma escolha, optar por uma ação entre um menu de ações possíveis em cada situação.

Segundo a perspectiva dominante na filosofia da ação, a teoria da decisão ou da escolha racional estabelece as condições formais que escolhas e preferências devem satisfazer. Ela não é uma teoria positiva, porque não diz nada sobre a medida em que as pessoas são racionais. Definir o que a preferência e a escolha racionais são significa, ipso facto, dizer como se deve racionalmente preferir e escolher. Embora existam muitas versões diferentes desta interpretação geral da teoria da escolha racional e haja um debate de fundo acerca dos detalhes filosóficos concernentes à questão de sua normatividade, é justo dizer que, durante a

\footnotetext{
${ }^{2}$ Esta será uma situação de escolha sob incerteza probabilística, que difere da situação de escolha sob incerteza estratégica, típica do contexto da teoria da decisão estratégica ou teoria dos jogos.
} 
segunda metade do século XX, o entendimento que a teoria da decisão é uma teoria normativa se tornou a forma padrão de abordagem da teoria da escolha racional entre os filósofos. Como Robert Nozick (1993:41) explica:

Uma elaborada teoria da ação racional tem sido desenvolvida por economistas e estatísticos e
colocada em uso generalizado tanto em estudos teóricos como políticos. Esta é uma teoria
matemática precisa, poderosa e tratável. Apesar de sua adequação como uma descrição do
comportamento real ter sido amplamente questionada, ela se destaca como a visão dominante
das condições que uma decisão racional deve satisfazer: é a visão normativa dominante.

É importante notar que aqui, como em todo o resto do texto, usa-se o termo genérico teoria da decisão racional para designar as várias teorias específicas - teoria da utilidade, teoria da utilidade esperada, teoria da escolha do consumidor - que têm como hipótese central agentes possuindo preferências bem ordenadas. De modo mais abstrato, diz-se que se trata de uma função escolha definida sobre um espaço de escolha, sendo que estas teorias explicam o comportamento como resultado de uma ação instrumentalmente racional: o agente fez a melhor escolha possível, dadas suas preferências. Muito embora a formulação matemática original da teoria da utilidade esperada remontar a Bernouli, no século XVIII, foi em Theory of Games and Economic Behavior, publicado em 1944, que von Neumann e Morgenstern deram o passo definitivo nessa direção. Nesta obra, os autores forneceram simultaneamente a abordagem axiomática para a teoria da tomada de decisão em condições de incerteza e a formalização da hipótese da utilidade esperada, dois séculos depois da definição original de Bernouli.

Em sua versão standard, a teoria da decisão racional ou da utilidade esperada baseiase em uma concepção de comportamento humano que envolve uma série de pressupostos, sendo que dentre os mais importantes encontram-se os seguintes: os agentes dispõem de uma estrutura determinada e ordenada de preferências (que representam seus desejos); essas preferências são completas (o agente prefere $a$ a $b$ ou $b$ a $a$ ou é indiferente entre $a$ e $b$ ) e transitivas (se o agente prefere $a$ a $b$ e $b$ a $c$, então necessariamente preferirá $a$ a $c$ ), exógenas (formadas fora do âmbito da decisão) e independentes, i.e. incomparáveis com aquelas dos demais agentes. Além disso, como esquematizado na figura que segue, supõe-se ainda que os agentes atribuam diferentes utilidades aos resultados possíveis de suas ações, ponderando-as com as probabilidades com que acreditam que esses resultados possam ser alcançados. Sendo as crenças do agente amiúde abaladas pela incerteza que envolve resultados específicos, a sua tomada de decisão vai considerar a média das utilidades que lhe trazem as ações adotadas em resposta às probabilidades de ocorrência dos diferentes estados, sua utilidade esperada. 
Abaixo, a figura 1 apresenta um esquema da escolha racional baseado na utilidade esperada:

Figura 1: Curso de Ação, Resultado, Utilidade, Probabilidade, Utilidade Esperada

\begin{tabular}{|c|c|c|c|c|}
\hline $\begin{array}{l}\text { Curso de } \\
\text { Ação }\end{array}$ & Resultado & Utilidade & Probabilidade & $\begin{array}{l}\text { Utilidade } \\
\text { Esperada }\end{array}$ \\
\hline \multirow[t]{3}{*}{$\mathrm{C}_{1}$} & $\mathrm{R}_{1,1}$ & $\mathrm{U}_{1,1}$ & $\mathrm{P}_{1,1}$ & $\mathrm{P}_{1,1} . \mathrm{U}_{1,1}$ \\
\hline & $\mathrm{R} 1,2$ & $\mathrm{U}_{1,2}$ & $\mathrm{P}_{1,2}$ & $P_{1,2} \cdot U_{1,2}$ \\
\hline & $\mathrm{R}_{1,3}$ & $\mathrm{U}_{1,3}$ & $\mathrm{P}_{1,3}$ & $\mathrm{P}_{1,3}$. U U1,3 \\
\hline \multirow[t]{2}{*}{$\mathrm{C}_{2}$} & $R_{2,1}$ & $U_{2,1}$ & $P_{2,1}$ & $P_{2,1}$. U $2_{2,1}$ \\
\hline & $\mathrm{R}_{2,2}$ & $\mathrm{U}_{2,2}$ & $\mathrm{P}_{2,2}$ & $P_{2,12} \cdot U_{2,2}$ \\
\hline
\end{tabular}

Fonte: Little, 1991: 49.

Consideremos que um agente encontra-se frente a um par de alternativas (cursos de ação possível) a fim de alcançar algum objetivo pré-estabelecido. Cada curso de ação acarretará um resultado com alguma probabilidade de ocorrência (refletindo as circunstâncias de risco ou incerteza). A figura 1 representa uma situação em que o agente possui dois cursos de ação possíveis $\left(\mathrm{C}_{1}\right.$ e $\left.\mathrm{C}_{2}\right)$, sendo que $\mathrm{C}_{1}$ pode acarretar três resultados $\left(\mathrm{R}_{1,1}, \mathrm{R}_{1,2}\right.$ e $\left.\mathrm{R}_{1,3}\right)$ e $\mathrm{C}_{2}$ dois resultados $\left(\mathrm{R}_{2,1}\right.$ e $\left.\mathrm{R}_{2,2}\right)$. Cada resultado, por sua vez, associa-se a uma utilidade $\left(\mathrm{U}_{\mathrm{i}, \mathrm{j}}\right)$ e a uma probabilidade $\left(\mathrm{P}_{\mathrm{i}, \mathrm{j}}\right)$ de ocorrência. Em primeiro lugar, assume-se que o agente é capaz de atribuir valores às utilidades decorrentes de cada resultado possível. Em seguida, assume-se também que ele poderá atribuir probabilidades a cada um destes resultados. Estas hipóteses compõem o quadro teórico a partir do qual o processo de tomada de decisões pode ser analisado.

Mas afinal, como o agente deverá escolher qual curso de ação tomar? Chegamos ao ponto em que se torna necessário definir uma regra de ação apropriada. Uma base proeminente de escolha é a chamada regra da utilidade esperada. Como se sabe, segundo essa abordagem, o agente atribui um valor ponderado para cada opção que consiste na soma das utilidades esperadas para cada um de seus resultados (a utilidade do resultado ponderada por sua probabilidade de ocorrência - $\mathrm{U}_{\mathrm{i}, \mathrm{j}}$ • $\mathrm{P}_{\mathrm{i}, \mathrm{j}}$ ). $\mathrm{O}$ agente então deve escolher a opção ou o curso de ação que the atribua a maior utilidade esperada. A vantagem da regra da maximização da utilidade esperada é que ela conduz ao maior ganho possível quando aplicada a um grande número de situações de escolha ao longo do tempo. No entanto, esta regra apresenta um problema: sua insensibilidade aos riscos. 
Suponhamos que os valores de $\mathrm{U}_{\mathrm{i}, \mathrm{j}}$ e de $\mathrm{P}_{\mathrm{i}, \mathrm{j}}$ sejam os descritos na figura 2, abaixo:

Figura 2: Um exemplo específico de Utilidade Esperada

\begin{tabular}{|c|c|c|c|c|}
\hline $\begin{array}{l}\text { Curso de } \\
\text { ação }\end{array}$ & Resultado & Utilidade & Probabilidade & $\begin{array}{l}\text { Utilidade } \\
\text { Esperada }\end{array}$ \\
\hline \multirow[t]{3}{*}{$\mathrm{C}_{1}$} & $\mathrm{R}_{1,1}$ & 1000 & 0,1 & 100 \\
\hline & $\mathrm{R}_{1,2}$ & -10 & 0,8 & -8 \\
\hline & $\mathrm{R}_{1,3}$ & -20 & 0,1 & -2 \\
\hline \multirow{2}{*}{$\mathrm{C}_{2} \longrightarrow$} & $\mathrm{R} 2,1$ & 700 & 0,1 & 70 \\
\hline & $\mathrm{R} 2,2$ & 20 & 0,9 & 18 \\
\hline
\end{tabular}

Fonte: Little, 1991: 50.

Neste exemplo, a utilidade esperada de $\mathrm{C}_{1}$ é 90 e a de $\mathrm{C}_{2}$ é 88. Isto significa que, de acordo com a regra da utilidade esperada, o agente deveria escolher $\mathrm{C}_{1}$. No entanto, existe uma probabilidade de 90 por cento de que a utilidade de $\mathrm{C}_{1}$ seja negativa, ao passo que as utilidades de $\mathrm{C}_{2}$ serão sempre positivas (700 ou 20). Caso supuséssemos ainda que esta se trata de uma escolha única - não repetível ao longo do tempo -, então eventuais perdas de hoje não poderiam ser compensadas por ganhos futuros. Sob essas circunstâncias, a regra da maximização da utilidade esperada não consegue lidar de forma adequada com o risco elevado de perda ${ }^{3}$.

Embora aparentemente inócuo, o pressuposto de que indivíduos em condições de incerteza devem decidir com base na utilidade esperada contém restrições adicionais em comparação com aquelas que se referem às funções de utilidade em condições determinísticas. Uma das mais importantes delas remete ao conceito de risco.

O risco refere-se a situações em que o tomador de decisão julga saber com certeza as probabilidades matemáticas dos possíveis resultados de suas alternativas de escolha, ao passo que incerteza refere-se a situações em que as probabilidades de resultados diferentes não

\footnotetext{
${ }^{3}$ A regra da maximização da utilidade esperada é a mais conhecida, porém não é a única regra de ação racional. Outra diretriz para o comportamento racional é a chamada regra maximin: aquela que maximiza o mínimo resultado ou, alternativamente, minimiza a máxima perda possível. Segundo o que prescreve o maximin, o agente precisa identificar a máxima perda ou o pior resultado possível em cada um dos cursos de ação (no caso do exemplo acima, o pior resultado possível é $-20 \mathrm{em} \mathrm{C} 1$ e 20 em C2.) e em seguida optar pela alternativa que seja a menos pior. Ou seja, no caso em pauta, o agente deveria optar por $\mathrm{C}_{2}$. A regra do maximin é claramente conservadora, no sentido de prescrever uma alternativa "avessa ao risco". Ela protege o agente das piores perdas, por um lado, mesmo que ao custo de impedir que ele possa alcançar os maiores - e mais arriscados - ganhos, por outro. É interessante notar que ambas as regras - da maximização da utilidade esperada e do maximin - são, cada uma a seu modo, como seus nomes já antecipam, estratégias de maximização. No entanto, nem todo comportamento racional reflete uma regra de maximização. Simon (1979) pretendeu justamente mostrar que muitas ações racionais estão submetidas a um processo decisório que ele referiu como uma busca pelo "satisfazimento" (satisfacing) em contraste à(s) regra(s) da maximização (maximizing).
} 
podem ser expressas com precisão matemática. De acordo com a teoria da decisão racional e consequentemente com a teoria da maximização da utilidade esperada, todas as situações de incerteza podem ser reduzidas a situações de risco, assumindo, por exemplo, uma probabilidade de 0,5 . Isto é referido como o conceito de "ignorância". O conceito de "aversão ao risco", por sua vez, refere-se às circunstâncias nas quais, quando enfrentam escolhas com retornos comparáveis, os agentes tendem a escolher a alternativa menos arriscada. A questão do risco precisa ser tratada mais a fundo, tendo em vista que nos testes de laboratório o comportamento factual dos agentes parece contradizer a hipótese da maximização da utilidade esperada ${ }^{4}$.

Na década de 1950, idade de ouro da teoria da racionalidade padrão, os êxitos alcançados pela programação linear pareciam justificar a fé na capacidade dos modelos de otimização explicarem todas as formas economicamente significativas de comportamento. Havia uma convicção mais ou menos generalizada de que era possível e justificável reduzir os fenômenos macroeconômicos a formas racionais de comportamento, e de representar todas as formas racionais de comportamento como problemas de maximização sob restrição. No entanto, como os modelos de tomada de decisão racional se voltaram para situações cada vez mais complexas, houve um correspondente aumento na complexidade dos cálculos e no refinamento dos algoritmos necessários para resolvê-los. Isso levantou a questão da legitimidade de se descrever indivíduos como capazes de executar processos de tomada de decisão daquela natureza, como as teorias econômicas estavam pressupondo. Alternativamente, havia a proposta de que os modelos de comportamento racional fossem interpretados da maneira tradicional, no sentido normativo, ou como técnicas que deveriam auxiliar na tomada de decisão, adequadas para o uso de especialistas.

Essa controvérsia viria a levar Simon $(1955,1957,1979)$ a avançar sua hipótese de racionalidade limitada (bounded rationality), lançando a polêmica contra a ideia de racionalidade perfeita e abrangente, a "racionalidade substantiva" adotada pela teoria da maximização da utilidade esperada. Uma das razões para as imperfeições do processo de deliberação humano que interessava particularmente a ele dizia respeito ao fato de que o raciocínio humano é uma atividade que consome recursos, i.e. uma atividade que envolve custos para o agente. Estes custos decorreriam da existência de limitações - ambientais, psicológicas, cognitivas - ao processo de deliberação que seriam incontornáveis para o intelecto humano, segundo o seu entendimento.

\footnotetext{
${ }^{4}$ Veremos abaixo que este é um dos aspectos mais relevantes, que baliza a concepção alternativa proposta pela teoria das perspectivas acerca da racionalidade factual dos agentes humanos.
} 
Os cenários regidos por aquilo que Simon caracterizou como racionalidade limitada dizem respeito a contextos reais nos quais os agentes encontram-se constrangidos por uma (ou mais) das seguintes circunstâncias: não dispõem de informação completa, não dispõem do tempo e/ou não dispõem dos meios cognitivos necessários para o cômputo absolutamente rigoroso e definitivo de qual será a melhor opção a seguir dentre diferentes cursos de ação alternativos. Portanto, mesmo aqueles indivíduos dispostos a tomar decisões racionais estariam incapacitados para tal e, consequentemente, estariam obrigados a fazer escolhas subótimas em situações complexas.

O modelo de Simon (1957: 198) da racionalidade limitada propõe que limitações cognitivas levam os decisores à construção de modelos simplificados para lidar com o mundo. Simon argumentou que o tomador de decisão:

\footnotetext{
Comporta-se racionalmente com respeito a este modelo [simplificado], e tal comportamento não é nem mesmo aproximadamente óptimo em relação ao mundo real. Para pever o seu comportamento, temos de compreender a maneira em que este modelo simplificado é construído, e sua construção será, certamente, relacionada com as suas propriedades psicológicas como a perceção, o pensamento e a aprendizagem animal.
}

No mesmo trabalho, Simon sugere uma estratégia cognitiva para explicar o comportamento dos agentes econômicos. Trata-se do princípio da "satisfazibilidade" (satisficing), que explica o comportamento dos consumidores que procuram por uma opção "boa o suficiente" em um ambiente incerto, onde a busca por alternativas é custosa. Satisfazer é uma decisão heurística que envolve escolher a primeira alternativa que preencha seus requerimentos mínimos. Satisfazer é simples em termos de operadores cognitivos, exigindo menos dos recursos mentais escassos. Contudo, pode levar a um comportamento subótimo dado que, ao encontrar uma opção aceitável, cessam a busca e a avaliação de outras alternativas possivelmente melhores.

Ocorre que pouco antes, naquela mesma época, uma solução diferente, engenhosa e bem sucedida para o dilema foi proposta por Milton Friedman (1953), proporcionando um novo ponto de referência para o mainstream. Isso significou que, não obstante a interpretação normativa fosse o entendimento padrão da teoria da escolha racional entre os filósofos particularmente no ramo da filosofia denominado "filosofia da ação" -, para a maioria dos economistas ela foi - e é - muito mais uma teoria positiva/descritiva do comportamento econômico. Uma contribuição importante para essa visão foi a influência do artigo seminal de Friedman, como argumentaremos abaixo. 


\section{Racionalidade: a abordagem Positiva da Teoria da Utilidade Esperada}

A tese de Friedman, desenvolvida em seu clássico artigo de 1953, Metodologia da Economia Positiva, constitui uma tentativa de defesa da aplicação do método popperiano à ciência econômica. Friedman se mostra partidário tanto da constatação empírica quanto da falsificação de teorias. “A evidência factual jamais 'prova' uma hipótese; pode, apenas, deixar de refutá-la e é isto, justamente, o que se entende ao dizer, de maneira um tanto inexata, que a hipótese foi 'confirmada' pela experiência” (Friedman, 1953: 169). A tese central desse artigo resume-se na defesa do suposto da racionalidade substantiva com base na proposição de que os economistas não deveriam preocupar-se em adotar pressupostos realistas. Isto porque o objetivo da ciência não é e nem pode ser encontrar pressupostos realistas para uma teoria, mas sim buscar aproximações simplificadas e idealizadas que proporcionem predições suficientemente ajustadas. Pode-se resumir sua posição da seguinte forma: se a predição de uma teoria mostrar-se válida, deve-se aceitar a teoria "como se" (o célebre as if friedmaniano) seus pressupostos fossem verdadeiros.

Não haveria grandes problemas na defesa da tese de que as hipóteses de qualquer teoria são sempre irrealistas, já que os pressupostos científicos consistem, necessariamente, de simplificações da realidade. Não poderia existir ciência caso houvesse a necessidade que os pressupostos teóricos fossem espelhos perfeitos da realidade. Além disso, o fato de contar com pressupostos supostamente mais realistas não bastaria para que uma teoria fosse aceita, pois nenhuma teoria pode ser testada comparando-se seus pressupostos diretamente com a realidade. No momento crucial para a ciência, no teste empírico, o que está em jogo e o que vale são as previsões que as teorias são capazes de fazer.

A tarefa da economia positiva é a de provar um sistema de generalizações passível de ser utilizado para fazer previsões corretas acerca das consequências de qualquer alteração das circunstâncias. O desempenho de uma tal economia será ajuizado em termos de precisão e do alcance das previsões em termos do ajuste que haja entre tais previsões e a experiência. Em suma, a economia positiva é ou pode vir a ser uma ciência "objetiva", exatamente como qualquer das ciências físicas. (Friedman: 1953: 4-5. Ênfase acrescentada).

O problema realmente começa com a segunda tese, a parte mais extravagante da proposta friedmaniana, que pode ser resumida no seguinte trecho de Blaug (1999: 141): “[...] Não apenas é desnecessário que os pressupostos sejam realistas, mas o fato de que eles não o sejam é uma vantagem positiva. Para que uma hipótese seja relevante, ela deve ser 
descritivamente falsa em seus pressupostos". Estas proposições geraram um foco de polêmica em torno à questão do "realismo dos pressupostos", bem como à questão do realismo em um sentido filosófico mais profundo. Em decorrência disso, é preciso ressaltar que, ainda que o próprio Friedman se alinhasse com uma postura popperiana e que autores como Blaug (1999) argumentem que sua posição seja essencialmente falseacionista, vários outros autores o identificam como um instrumentalista (Nagel, 1963; Caldwell, 1980; Pheby, 1988), sendo que o instrumentalismo de modo algum se compatibiliza com a defesa veemente do realismo feita por Popper.

De acordo com Friedman, embora os indivíduos não possuíssem as ferramentas formais para calcular a melhor forma de agir maximizando suas utilidades esperadas, eles se comportavam "como se" assim o fizessem. Ou seja, agentes econômicos se comportariam como os ciclistas que se mantêm em equilíbrio dinâmico, mesmo sem o conhecimento das complexas equações da dinâmica do movimento, ou como os jogadores de sinuca que realizam feitos extraordinários calculando mentalmente as trajetórias de suas bolas de bilhar, muito embora ignorantes das leis da mecânica. Friedman completou a hipótese do as if com a alegação adicional de que as preferências individuais não eram observáveis, e que de fato elas seriam irrelevantes para prova da validade de uma teoria econômica. A fim de explicar por que essa posição obteve sucesso tão prolongado, é útil examinar um pouco mais cuidadosamente os termos do problema.

Sendo a escolha o resultado de uma atividade de computação racional, importa o quão complexos são os cálculos necessários para a racionalidade. De acordo com estes pressupostos, a teoria da decisão racional prescreve para os agentes econômicos a melhor maneira de alcançar seus objetivos. Para enfraquecer o caráter normativo da racionalidade canônica, que não se coadunava bem com sua ênfase no caráter positivo da ciência econômica ${ }^{5}$, Friedman presume que aqueles agentes que não agem em conformidade com o postulado da racionalidade seriam gradualmente excluídos do mercado por meio de um processo de seleção que permitiria apenas aos agentes "racionais" sobreviverem.

Esse estratagema darwinista conduz a uma teoria econômica que assume caráter patentemente positivo. Ou seja, a teoria se proporia a descrever como os agentes se comportam de fato: maximizando seus resultados esperados. Sob este prisma, seria inútil investigar os aspectos psicológicos envolvidos na tomada de decisão, pois, no máximo, eles poderiam ajudar na explicação dos motivos pelos quais certos indivíduos seriam incapazes de

\footnotetext{
${ }^{5}$ Qualificativo este, aliás, que Friedman faz questão de deixar bem claro já no título do artigo - "The methodology of positive economics".
} 
se comportar de uma forma totalmente racional, o que os levaria a serem excluídos do mercado.

No contexto da discussão que acaba de ser alinhavada, o dado realmente digno de nota é o seguinte: muito embora a concepção filosófica que subjaz a teoria da decisão nunca tenha entendido que o seu estatuto fosse outro que não o de uma teoria normativa acerca da racionalidade (subseção 2.1, acima), no mainstream da economia durante muito tempo se acreditou, tácita ou explicitamente, que tanto a teoria da decisão quanto o postulado da racionalidade, uma vez utilizados na formulação das teorias econômicas padrão, representavam não o "dever ser", mas principalmente o "é" do comportamento humano. Acreditamos que o artigo seminal de Milton Friedman (1953) forneceu um recurso intelectual engenhoso. Em tese, a proposição de certa ambiguidade (normativo/positiva) para o papel postulado da racionalidade na economia. Ambiguidade esta que se desfaz tão logo entra em cena o argumento darwinista segundo o qual apenas agentes maximizadores de suas utilidades esperadas sobreviveriam no mercado. Ou seja, ao fim e ao cabo, acaba-se por reforçar o caráter positivo que a teoria da decisão racional assumiu na ciência econômica.

Não obstante, por uma série de razões, cada vez mais o suposto caráter positivo da racionalidade substantiva assumido pela economia mainstream parece ser colocado em causa. Nesse sentido, os insights da economia comportamental desenvolvidos por Kahneman e Tversky têm sido fundamentais para estabelecer novas propostas teóricas, a partir dos resultados empíricos encontrados nas investigações em curso, além de orientarem tentativas instigantes para reformular muitos aspectos da teoria econômica e financeira. As novas pontes entre as disciplinas podem ser largamente atribuídas à sua pesquisa inovadora na fronteira entre economia e psicologia.

Muito embora os resultados experimentais já estivessem questionando a validade factual do modelo padrão da ação racional desde a década de 1950 com o paradoxo de Allais (1953), e o estudo empírico dos processos de decisão em empresas conduzidas por Cyert, Simon e Trow (1956), a abordagem de Kahnemann e Tversky se diferencia em alguns aspectos centrais das propostas apresentadas anteriormente. Uma vez que não estava limitada a determinados axiomas, ela pôde reestruturar o problema, de modo a fazer referência aos processos mentais (psicológicos) efetivamente envolvidos na maneira como as pessoas inferem, deliberam e escolhem seus cursos de ação. Além disso, a chamada teoria das perspectivas também logrou encaixar-se de forma coerente dentro do quadro analítico da racionalidade limitada de Simon, como Kahnemann e Tversky explicitamente reconheceram. 


\section{RACIONALIDADE: A ABORDAGEM POSITIVA (DESCRITIVA) DA TEORIA DAS PERSPECTIVAS}

Diferentemente da proposta normativa da teoria da decisão, a abordagem positiva (ou descritiva), que primordialmente - porém não exclusivamente - é perseguida por psicólogos e neurocientistas $\operatorname{cognitivos}^{6}$, tem por objetivo caracterizar como as pessoas realmente são no tocante à racionalidade. Nesse contexto, importa mencionar que atribuição de razões às ações também desempenha um papel fulcral na previsão do comportamento dos agentes: ao conhecer a intenção prévia de um agente de levar a cabo uma dada ação, poderemos prever com alguma precisão o seu comportamento. No contexto da economia comportamental, o que se busca é desvendar os mecanismos cognitivos e os processos psicológicos que fundamentam os padrões de raciocínio que são de fato observados em testes de laboratório. Nessa linha de investigação, um dos programas de pesquisa atualmente mais destacados é aquele conhecido como Heurísticas e Vieses. Ele surgiu nos anos 1970, a partir da série de trabalhos de Daniel Kahneman e Amos Tversky (cf., por exemplo, Kahneman e Tversky 1972, 1973, 1979; Tversky e Kahneman, 1971, 1974 e Kahneman, Slovik e Tversky, 1982), tendo rapidamente se tornado um marco nas pesquisas comportamentais voltadas para o estudo da racionalidade.

Mas o que, exatamente, os resultados experimentais destas pesquisas revelaram? Basicamente, que os sujeitos humanos não possuem a competência racional subjacente para lidar com uma vasta gama de tarefas de raciocínio. E que, para resolverem seus problemas de tomada de decisão, ao invés da racionalidade substantiva que pressupõe a teoria da decisão tradicional, os sujeitos lançam mão de uma coleção de regras intuitivas simples: as heurísticas. Estas heurísticas, apesar de serem úteis no sentido de simplificar a complexidade normalmente envolvida no processo de tomada de decisões, também os torna mais propensos a erros, padrões contra-normativos e/ou preconceitos, os chamados vieses.

A partir destas descobertas, começou a ser elaborada uma teoria da racionalidade com propósitos descritivos, ou seja, uma teoria cuja abordagem desde o seu surgimento é patentemente positiva. O seu propósito é explicar o comportamento factual dos agentes, tal como observado nos testes de laboratório. Baseada nos conceitos de heurísticas e vieses, ela foi chamada de teoria das perspectivas ou teoria dos prospectos (Prospect Theory). (Kahneman e Tversky, 1979). À luz da filosofia da ação, neste artigo analisa-se o papel da

\footnotetext{
${ }^{6}$ Primordialmente, porém não exclusivamente, tendo em vista que foi este exatamente a abordagem que a economia tradicional conferiu à racionalidade no contexto das suas teorias, e que a economia comportamental também reivindica, como se verá abaixo.
} 
racionalidade na economia. Nosso intuito foi problematizar o papel normativo exercido pela racionalidade na filosofia da ação, contrapondo-o ao papel positivo exercido na economia (seja em sua versão mainstream, seja em sua versão comportamental). Ou seja, o artigo propõe-se a discutir se o comportamento humano factual observado nos testes de laboratório de fato colocaria em questão os padrões canônicos de racionalidade.

A teoria das perspectivas consiste em uma tentativa de explicação para as exceções dos pressupostos padrão acerca do comportamento racional encontradas em observações realizadas em ambiente controlado. Os teóricos da teoria das perspectivas categorizaram inconsistências com o pressuposto da racionalidade em uma série de problemas, abaixo relacionados:

(a) efeito "enquadramento" ou framing: situações nas quais os agentes fazem escolhas ou tomam decisões diferentes quando o mesmo problema é apresentado de maneiras distintas;

(b) preferências não-lineares: as pessoas não raramente fazem escolhas que são inconsistentes com as hipóteses tradicionais sobre suas funções de preferência. Considere a transitividade. Se $a$ é preferível a $b$ e $b$ é preferível a $c$, então $a$ necessariamente precisa ser preferível a $c$. Significa que, quando os indivíduos escolhem $c$ ao invés de escolherem $a$, então eles não estão se comportando de acordo com aquilo que prevê a racionalidade econômica;

(c) a aversão ao risco e a procura pelo risco: tampouco é incomum que indivíduos optem, simultânea e conscientemente, por aceitarem propostas injustas para evitar o risco (por exemplo, por meio da compra de seguro de vida) e propostas injustas que aumentam o risco (por exemplo, jogando em caça-níqueis de cassinos);

(d) fonte: o mecanismo pode importar mesmo se os resultados prováveis de atividades forem idênticos. As pessoas podem pagar mais por causa da maneira como um produto é embalado, mesmo quando eles sabem serem idênticos os conteúdos e quando pretendem descartar imediatamente a embalagem.

(e) aversão à perda: perdas potenciais têm maior efeito negativo do que o efeito positivo gerado por ganhos potenciais relativamente iguais. A assimetria observada nestas diferenças é demasiado grande para ser explicada somente pelo efeito renda.

Dados os vieses ou desvios da racionalidade substantiva constatados nos experimentos, os autores procuraram identificar quais as principais heurísticas de julgamento (atalhos cognitivos utilizados pelos agentes para auxiliar na tomada de decisões). Kahneman e Tversky identificaram três principais grupos de heurísticas: (i) representatividade (representativeness), (ii) disponibilidade (availability) e (iii) ancoragem e ajustamento (anchoring and ajustment) (Tversky e Kahneman, 1974). 
A heurística da representatividade refere-se à tendência de indivíduos avaliarem a probabilidade de um evento pelo nível com que ele se assemelha a outro. Ocorre que utilizar esta abordagem para se balizar frente a decisões que envolvem probabilidade pode conduzir a sérias distorções de julgamento, pois a similaridade entre eventos não precisa obedecer (e amiúde não obedece) aos preceitos da teoria das probabilidades. Já a heurística da disponibilidade diz respeito à forma como as pessoas avaliam a probabilidade de ocorrência de um evento pela facilidade com a qual os casos são trazidos à mente. Assim, eventos são julgados tanto mais prováveis, quanto mais fácil for para o sujeito imaginá-los acontecendo. Finalmente, a heurística da ancoragem e ajustamento faz alusão à "âncora", metáfora que representa algum valor de referência, que está de antemão disponível ao tomador de decisão. Agentes fazem estimativas a partir deste valor inicial, que é ajustado para possibilitar a decisão que será tomada.

Conforme visto acima, uma das razões para o grande impacto do programa de pesquisa Heurísticas e Vieses foi o fato de ter lançado dúvidas sobre a acuidade do conceito de racionalidade substantiva, assumido pelo maisntream da economia. Segundo a teoria da utilidade esperada, as utilidades dos resultados são ponderadas por suas respectivas probabilidades. No entanto, existe uma série de resultados experimentais sugerindo que as escolhas dos agentes sistematicamente violam este princípio. Os testes indicam uma tendência por parte dos indivíduos de superestimar resultados que são considerados como certos, em relação a resultados que são considerados como apenas prováveis. Significa dizer que os indivíduos, ao compararem eventos que acreditam serem certos com eventos relativamente parecidos, porém incertos, tendem a atribuir maior peso aos eventos do primeiro tipo. Este fenômeno foi denominado "efeito certeza". O melhor contraexemplo da teoria da utilidade esperada que explora o efeito certeza foi apresentado pelo economista francês Maurice Allais (1953) Kahneman e Tversky (1979) conduziram alguns pares de experimentos envolvendo ganhos monetários que consistem em uma variação do exemplo apresentado por Allais. Reproduzimos destes abatro abemplos

Problema 1: os indivíduos precisavam escolher entre duas as alternativas, conforme segue: Alternativa A: Receber $\$ 2.500$, com probabilidade 0,33 ; receber $\$ 2.400$, com probabilidade 0,66; receber $\$ 0, \quad$ com probabilidade 0,01 . Ou: Alternativa B: Receber \$2.400, com certeza, i.e., com probabilidade 1 . Problema 2: os indivíduos teriam que escolher entre as duas alternativas seguintes: Alternativa $C$ : Receber $\$ 2.500$, com probabilidade 0, 33; receber $\$ 0$, com probabilidade 0,66 . $\mathrm{Ou}$ : 
Alternativa D: Receber $\$ 2.400$, com probabilidade 0, 34; receber $\$ 0$, com probabilidade 0, 66 .

No problema 1, constatou-se que uma parte significativa dos indivíduos (82 por cento) preferiu a alternativa $B$ à alternativa $A$. Já no problema 2, observou-se uma preferência massiva (83 por cento) pela alternativa $\mathrm{C}$ em detrimento da alternativa $\mathrm{D}$. O ponto é que este padrão de preferências é obviamente incompatível com a regra da utilidade esperada. Efetivamente, fazendo $\mathrm{U}(\$ 0)=0$, o perfil de preferências exibido no problema 1 implica que:

$$
\begin{aligned}
& \mathrm{U}(\$ 2.400)>0, \\
& 33 \mathrm{U}(\$ 2.500)+0,66 \mathrm{U}(\$ 2.400)+0, \\
& 01 \mathrm{U}(\$ 0) \text { ou, equivalentemente, que } \\
& 0,34 \mathrm{U}(\$ 2.400)>0,33 \mathrm{U}(\$ 2.500)
\end{aligned}
$$

Por outro lado, o perfil exibido no problema 2 implica a exata reversão desta inequação.

Os experimentos têm mostrado que os agentes são avessos à perda, geralmente parecendo não gostar de perder com mais ou menos o dobro da intensidade que gostam de ganhar. Tal fenômeno tem sido observado em diversos estudos experimentais conduzidos sob uma ampla variedade de condições.

Ainda acerca da questão do risco e sua relação com o "efeito enquadramento", outro experimento é bastante significativo (Kahneman e Tversky, 1979: p. 272):

Problema 3: Suponha que você ficou $\$ 1000$ mais rico. Escolha entre:

Alternativa A: ganhar $\$ 1000$ com probabilidade 0.5 e não ganhar nada também com probabilidade 0,5. Ou:

Alternativa B: ganhar $\$ 500$ com certeza.

Problema 4: Assuma que você ganhou \$2000. Escolha entre:

Alternativa C: $50 \%$ de chance de não perder nada e 50\% de chance de perder $\$ 1000$. Ou:

Alternativa D: Uma perda certa de $\$ 500$.

Os que responderam o problema 3 comportaram-se de modo avesso ao risco, optando pelo ganho certo (resposta B). Isso ocorreu para a grande maioria que participou do experimento. Ao passo que, no problema 4 a resposta foi a favor de arriscar, ou seja: optaram pela alternativa C. A grande maioria dos agentes que se submeteu a esse experimento, ao escolher as respostas B e C, violou o axioma da independência da teoria da utilidade esperada, exatamente do modo como ocorreu com o clássico experimento de Allais. Os problemas 3 e 4, em termos de utilidade esperada, são o exatamente o mesmo. De fato, a grande maioria dos indivíduos se comporta como tomadores de risco diante de um problema apresentado em 
termos de perda (Problema 4), enquanto se comportam como avessos ao risco quando o mesmo problema é apresentado em termos de ganho (Problema 3). Esta incoerência descrita acima é denominada "efeito enquadramento", e ilustra como a representação mental (framing) de um problema pode ser crucial para se entender o comportamento individual.

Segundo a teoria das perspectivas, o efeito certeza contribui para que haja um comportamento diferenciado dos agentes em relação ao risco, dependendo se a situação envolve ganhos ou perdas. No primeiro caso, a aversão ao risco é acentuada pelo efeito certeza, já que há um aumento da atração por resultados considerados certos. Quando são as perdas que estão em jogo, ocorre o inverso: há um comportamento afeito aos riscos. Há, portanto, uma preferência por riscos com perdas maiores que são meramente prováveis, em comparação com uma perda menor que é vista pelo agente como certa, por apresentar maior probabilidade. Essa assimetria foi denominada por Kahneman e Tversky (1979) de "efeito reflexão". A assimetria entre a aversão e a afeição ao risco é a razão do formato da curva de utilidade em "S" da teoria das perspectivas, em substituição ao formato tradicional de "U" invertido da teoria da utilidade esperada.

Nesta curva em formato de "S", destacam-se os seguintes aspectos: i) a manutenção, como na teoria da utilidade esperada, de uma função valor, mas agora definida sobre ganhos e perdas e não mais sobre riqueza total; ii) a concavidade no domínio dos ganhos e convexidade no domínio das perdas e iii) a maior inclinação das perdas em relação aos ganhos. Ou seja, a expectativa de perder $\$ X$ produz maior aversão do que a atração provocada pela possibilidade de ganhar \$X (Kahneman; Tversky, 2000, p. 3). Estes aspectos podem ser visualizados na Figura 3, abaixo, onde encontramos um esquema comparativo entre as Teorias da Utilidade Esperada e das Perspectivas. 
Figura 3: Esquema Comparativo: Racionalidade Substantiva versus Racionalidade Limitada
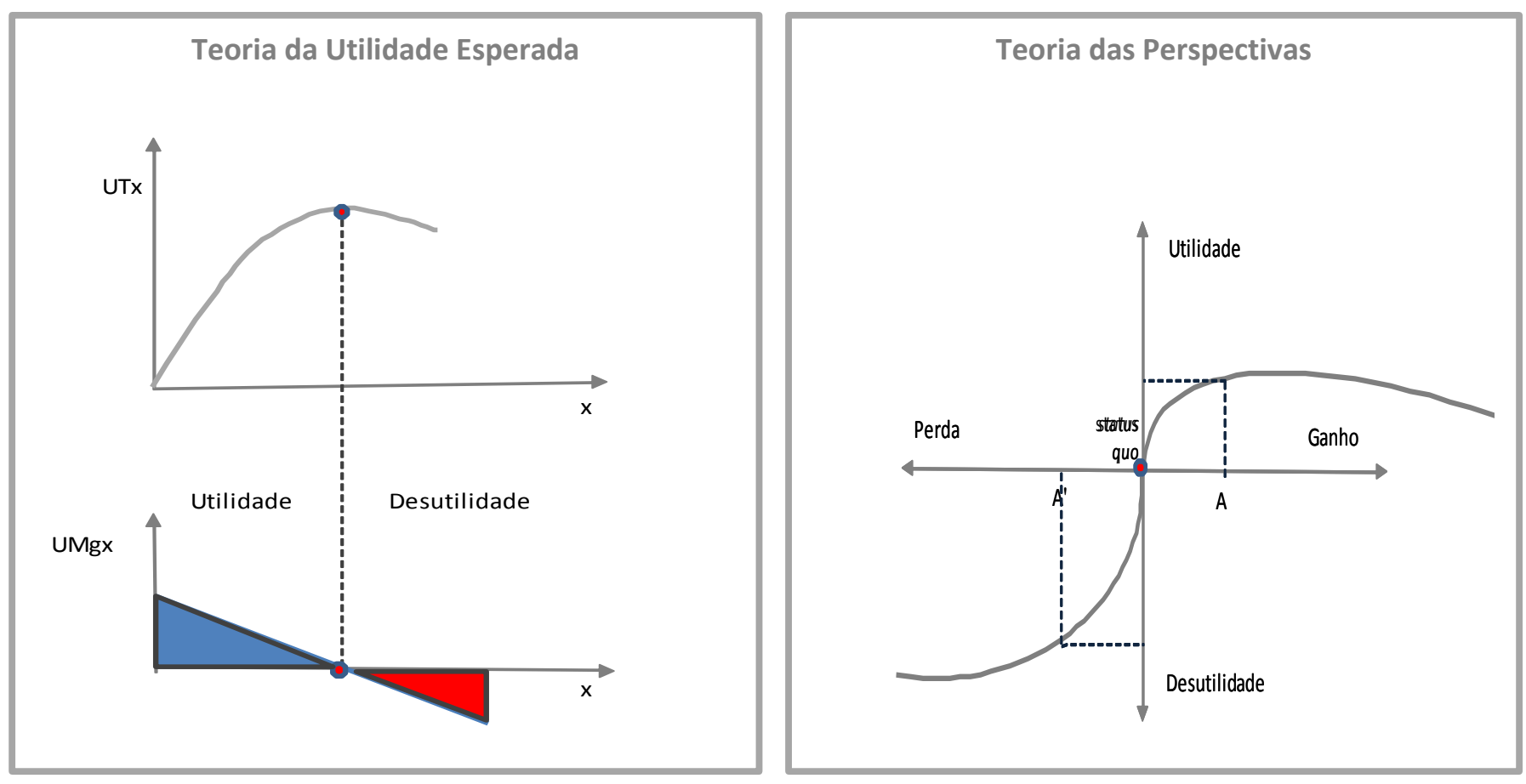

Fonte: Elaboração Própria.

Kahnemann e Tversky sugerem que, para compreender uma decisão, os processos cognitivos que estão em sua base devem ser cuidadosamente analisados. Assim, é necessário entender como as pessoas representam problemas, como o complexo processo de edição é realizado e como a construção de modelos mentais é conduzida a fim explicar como um agente toma uma decisão particular. Uma das principais conclusões dos autores foi a de que, quando as decisões são tomadas em condições de elevada incerteza, isto é, condições mal estruturadas em termos de uma hierarquia e de um conjunto de regras, seus resultados não podem ser totalmente avaliados por parte dos agentes. Isso ativa um processo de pesquisa que se destina a enquadrar todos os elementos envolvidos na decisão.

O problema central nessas situações é a busca de conhecimentos relevantes. Assim, os agentes não só devem reunir informações, mas também devem ser capazes de selecionar as informações que são efetivamente relevantes para seus fins e assimilá-las no sistema de conhecimento que já possuem. Para isso, eles devem ter um nível de competência adequado à situação de escolha, assim como implementar as competências de aprendizagem e de resolução de problemas que são totalmente diferentes (e muito mais complexas que) a racionalidade perfeita presumida pela teoria tradicional.

O núcleo do processo de tomada de decisão seria a atividade de pesquisa e aprendizagem, que fornece aos agentes as informações e os conhecimentos que necessitam 
para atingir seus objetivos. A escolha é apenas o estágio final do processo de tomada de decisão e é de importância secundária. A parte mais importante do processo é a capacidade dos indivíduos para formular e resolver problemas. Tanto a racionalidade limitada de Simon quanto a abordagem da economia comportamental apontam no sentido de que um dos aspectos cruciais do processo de tomada de decisão é a capacidade de construir novas representações de problemas.

O modo como os modelos são usados por indivíduos para enquadrar os problemas mentais está se tornando uma questão crucial a ser abordada pela teoria da decisão: uma questão que vai render um melhor entendimento das atividades humanas dentro e fora das instituições de mercado.

Com o enfraquecimento da abordagem de Friedman, as características cognitivas dos processos de escolha voltam a alcançar posição central. Seguir esse caminho implica em reconectar economia e psicologia, com o intermédio da filosofia da ação: uma tarefa exigente e relevante, que levanta questões sobre um dos princípios fundamentais da construção neoclássica da teoria econômica.

\section{CONSIDERAÇÕES FINAIS}

Mas afinal o que, exatamente, os resultados experimentais de Kahneman e Tversky (e de tantos outros economistas comportamentais e cientistas da cognição que obtiveram resultados semelhantes) revelaram? O comportamento humano observado nos testes empíricos realmente coloca em questão os padrões canônicos de racionalidade? Pelo que se viu nas seções anteriores, existem dois cenários possíveis, cada um dos quais contemplando um papel distinto para o suposto da racionalidade. A tomada de posição em defesa de cada papel, por sua vez, enseja uma questão, endereçada para o grupo que a sustenta. Na primeira situação, predominantemente defendida pelos filósofos da ação, a teoria da racionalidade consiste em uma abordagem normativa do comportamento humano. Se a abordagem é normativa, ou seja, se estamos a tratar de uma concepção da teoria da decisão racional consoante a qual o papel da racionalidade é mostrar como "devem ser" tomadas as decisões a partir dos mais rigorosos padrões estabelecidos, a resposta à pergunta formulada acima é não.

Os comportamentos desviantes, os vieses cognitivos sistemáticos encontrados nos experimentos empíricos não colocam em questão o postulado da racionalidade, na medida em 
que não se pode pretender refutar um enunciado ou uma teoria que não tenha nem almeje ter caráter descritivo, ou seja, uma teoria que não pretende nem explicar nem prever como o processo decisório do agente humano efetivamente se dá.

Não obstante, ainda assim este cenário coloca os filósofos da ação em uma situação delicada. Se a hipótese da decisão racional, enquanto proposição normativa, não condiz com o comportamento factual dos agentes em uma ampla gama de situações sistematicamente observadas em ambiente controlado, então não significa isto que a diretriz de racionalidade adotada como norma é inapropriada? Ou, alternativamente: se os agentes reais não se comportam da maneira como deveriam, a questão importante não passaria a ser por que eles estão cometendo tais "erros"? Ou seja: se a concepção canônica de racionalidade raras vezes é observada, não significa que ela impõe aos agentes um patamar de expectativas acerca da correção de raciocínio para a tomada de decisão elevado demais e portanto inviável do ponto de vista da escolha real?

Já a segunda abordagem possível, que é predominantemente defendida por economistas da corrente dominante, incluindo aqui os praticantes da teoria clássica dos jogos, assim como pelos teóricos da economia comportamental, enfatiza o caráter positivo (ou descritivo) da teoria da racionalidade com respeito ao comportamento humano. Neste caso, a resposta à pergunta que abre a seção é claramente sim. No sentido metodológico, os resultados experimentais desviantes seriam contraexemplos, anomalias ou casos recalcitrantes, se quiséssemos adotar uma linguagem kuhniana.

Aqui, a pergunta endereçada aos teóricos do mainstream da economia, alinhados à concepção de que a teoria da decisão racional desempenha um papel descritivo nas teorias econômicas (i.e. tem por objetivo explicar e prever o comportamento do agente) é a seguinte: se a hipótese da decisão racional, enquanto proposição descritiva, não condiz com o comportamento humano factual dos agentes reais em inúmeras situações empíricas, esse fato não significa que ela deveria ser abandonada e substituída por outra que reflita com mais acuidade o comportamento observado, como a hipótese da racionalidade limitada, por exemplo? Essa é justamente a posição de muitos economistas comportamentais: a implicação da prova empírica é que a teoria da escolha racional não é uma boa teoria descritiva e deve ser substituída por outra que seja melhor para prever e explicar o comportamento e as decisões humanas.

Importa frisar que diferentes programas de investigação possuem visões muito distintas sobre as implicações do desvio sistemático do comportamento humano real em relação àquilo que racionalmente deveria ser feito. Há muito para os filósofos, economistas, 
psicólogos cognitivos e outros cientistas do comportamento resolverem sobre essas várias posições e muito trabalho está em andamento. Porém, é importante observar que a posição que a teoria da escolha racional é normativa e positiva simultaneamente, como aquela proposta (ou pelo menos sugerida) por Friedman em seu artigo seminal, acaba por fechar a porta para essa discussão, efetivamente impedindo que se avance na discussão de questões levantadas pelos debates em filosofia da economia aqui referidos.

\section{REFERÊNCIAS BIBLIOGRÁFICAS}

ALLAIS, M. Le Comportement de l'Homme Rationnel devant le Risque, Critique des Postulats et Axiomes de l'Ecole Americaine. Econometrica, n. 21, p. 503-546, 1953.

ANSCOMBE, G. E. M. Intention. Cambridge MA: Harvard University Press, 1957.

BLAUG, M. Kuhn versus Lakatos or paradigms versus research programmes in the history of economics. In: LATSIS, Spiro (ed.) Method and appraisal in economics. Cambridge: Cambridge University, 1976, p. 149-180.

. Metodologia da economia - ou como os economistas explicam. São Paulo: Editora da Universidade de São Paulo, 1999.

CALDWELL, B. A critique of Friedman's methodological instrumentalism. Southern Economic Journal, v. 47, p. 366-374, 1980.

CYERT, R. M.; SIMON H. A.; THROW, D. Observation of a business decision. Journal of Business, n. 29, p. 237-248, 1956.

DAVIDSON, D. Essays on Action and Events. Oxford: Clarendon Press, 1980.

FERNANDEZ, B.; VERISSIMO, L.; COUTO, D. (Org.) . Por que Razão? Razões para Acreditar, para Agir e para Preferir. Porto: Universidade do Porto, 2017.

FRIEDMAN, M. The methodology of positive economics. In economics. Chicago: University of Chicago, 1966 [1953], pp. 3-46. Essays in positive

KAHNEMAN, D. Maps of Bounded Rationality: Psychology for Behavioral Economics. The American Economic Review, n. 93, v.5, pp. 1449-1475, 2003.

KAHNEMAN, D.; TVERSKY, A. Subjective probability: a judgment of representativeness. Cognitive Psychology, n. 3, p. 430-454, 1972.

. On the psychology of prediction, Psychological Review, n. 80, p. 237-25, 1973.

. Prospect Theory: an analysis of decision under risk. Econometrica, n. 47, v.2, p. 263-291, March 1979. 
. (Eds.) Choices, values and frames. New York: Cambridge University Press, 2000.

KAHNEMAN, D.; SLOVIK, P. TVERSKY (eds.), Judgment under uncertainty: heuristics and biases. New York and Cambridge: Cambridge University Press, 1982.

KUHN, T. A estrutura das revoluções científicas. São Paulo: Perspectiva, 1997 [1969].

LITTLE, D. Varieties of Social Explanation: an introduction to the philosophy of social science. Colorado: Westview Press, 1991.

MIGUENS, S. Racionalidade. Porto: Campo das Letras, 2004.

NAGEL, E. Assumptions in economic theory. American Economic Review. Papers and Proceedings v. 53, p. 211-219, 1963.

NOZICK, R. The Nature of Rationality. Princeton, NJ: Princeton University Press, 1993.

PHEBY, J. Methodology and economics. London: MacMillan Press, 1988.

SIMON, H. A. A Behavioral Model of Rational Choice. Quarterly Journal of Economics, 1955, n. 69, vol.1, pp. 99-118.

. Models of Man. Nova York, John Wiley, 1957.

. From Substantive to Procedural Rationality. In HAHN, F. and HOLLIS, M. (eds), Philosophy and Economic Theory, 1979.

STEIN, E. Without Good Reason. Oxford: Clarendon Press, 1996.

TVERSKY, A.; KAHNEMAN, D. The Belief in the law of small numbers. Psychological Bulletin, 1971, n. 76, p. 105-110, 1971. 